\title{
Learning from Germany
}

\author{
Kirsten Harrison \\ Junior, BCRP, Cal Poly.
}

\begin{abstract}
The CRP Department believes that international exchanges and cross-cultural studies are fundamental for a planner's education. Our students are exposed to international case studies, are encouraged to travel and study abroad, and share classrooms with international students and research fellows visiting Cal Poly. In this article, Kirsten Harrison tells us about her life-changing experience studying in Germany.
\end{abstract}

\begin{abstract}
A $s$ a junior in the City and Regional Planning Department at Cal Poly San Luis Obispo I studied abroad in Berlin, Germany. Studying abroad was something I always wanted to do and it was even better than I thought it would be. I didn't know I would end up in Berlin, but I am so glad that I did. Looking back, it was the perfect city for me to be in. An interestingly fused city of past, present and future, with so much understanding and hope. I like to think there is magic there in Berlin. I cannot wait to go back.
\end{abstract}

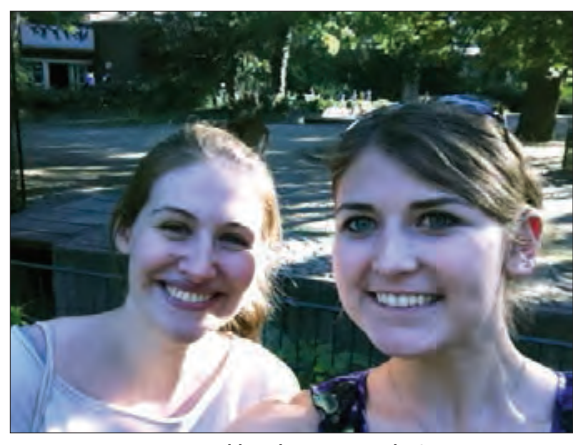

Kirsten and her host at Berlin's zoo.

program, the field trips included in this program are really what sold me on IES Abroad. We went to St. Petersburg, Russia for a week and to Paris, France for a week. On each one of these weeklong field trips the hotels were included, two meals a day were included, and most of the activities in a day were included: the best museums, shows, churches, and tours. It was outstanding.

We also went to guest lectures and visited with partner universities and students to talk about relevant metropolitan issues

In particular, I was in the Metropolitan Studies program, which complemented the City and Regional Planning program at $\mathrm{Cal}$ Poly nicely. I learned so much! My classes specifically looked at metropolitan issues in comparative and interdisciplinary approaches. My classes ranged from visual culture to literature and film to metropolitan development. Each class brought something different to my educational experience. Overall, I learned a lot and the coursework was very similar to my Cal Poly workload, which made it challenging, but also very stimulating and engaging.

My living situation was wonderful while in Berlin. I chose to stay in a homestay and was placed with a local Berlin resident. The process was therefore very easy for me. I simply took a questionnaire before I arrived in Berlin and my program placed me with a suitable host. My host was great. She was a young girl about my age who had a great deal in common with me. It was just the two of us living in an apartment really close to school and the center of the old city of Berlin. We would often go shopping together, or to the park, or even the zoo. She spoke English very well and would help me with my German. I was very lucky with this homestay. Others in my program lived further away from school or things to do.

Possibly the coolest thing about my Study Abroad program itself was the included field trips. When I was choosing a in each city. It was such a good traveling experience and we did all of these amazing things in a safe and well-planned way with guides that had done it before. We did have homework on these trips from our teachers at our home school in Berlin, but that was okay because it tied it in nicely to our curriculum. It did make it a nice comparison to Berlin.

Kirsten with the IES Abroad Berlin Metropolitan Studies Fall 2013 group in Berlin.

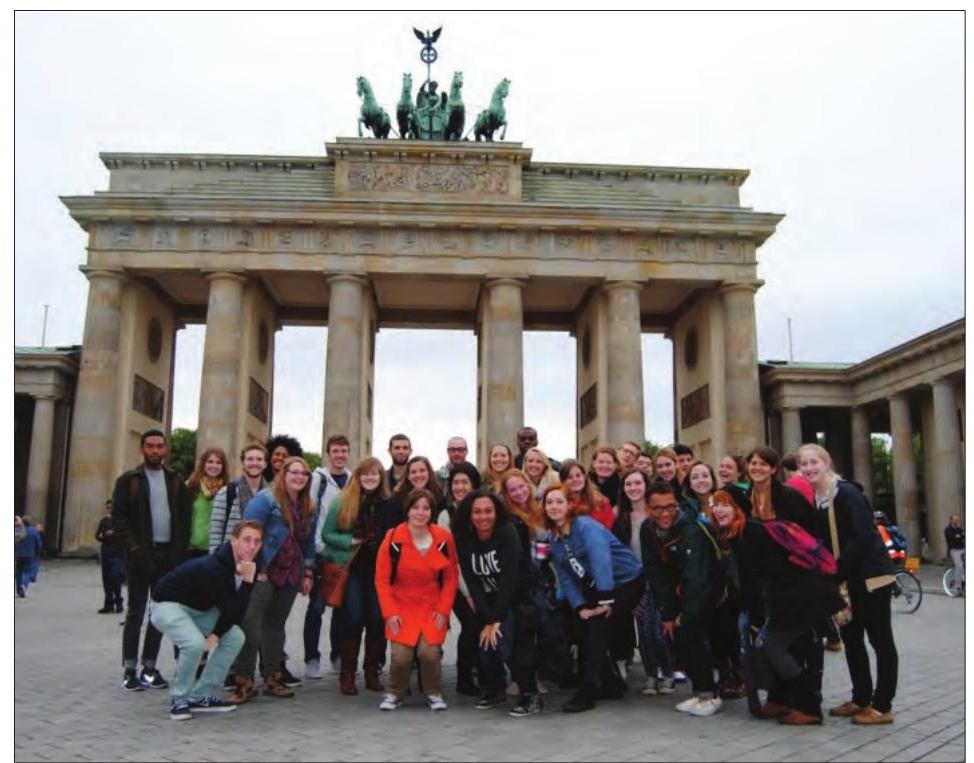


In addition to these weeklong field trips, we went on a couple weekend field trips with our program to Dresden and Potsdam for academic purposes, which was great as well. Then, of course, there was private traveling. With my friends that I made abroad I traveled all over! It was such a confidence boost to be able to travel! It broadened my perspective about the world around me to be able to travel to different countries and see the different ways of living and learning, but it also made me learn about myself and see how big the world really is. It really just made me want to travel more.

I can't wait for my next trip!

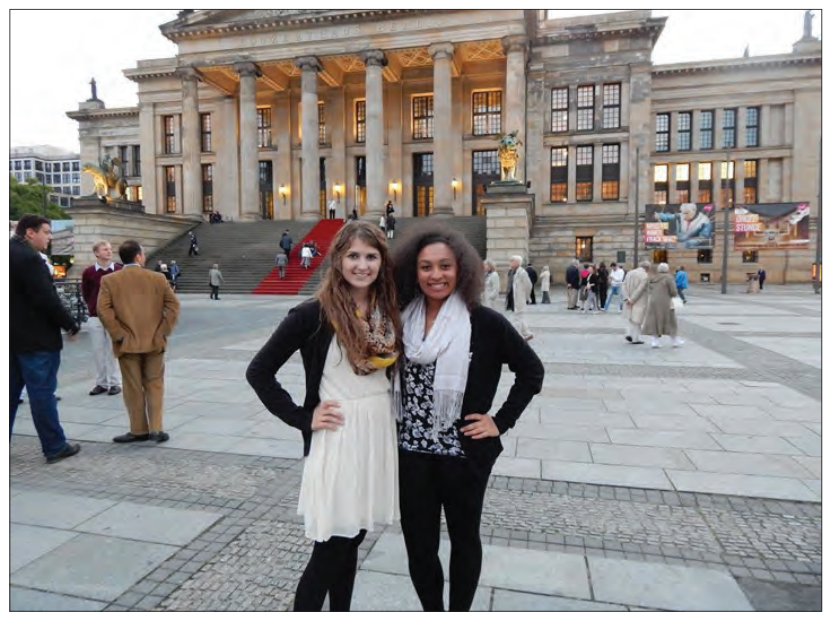

Kirsten with a colleague in front of the Konzerthaus (the Concert Hall) for the Berlin Symphony Orchestra. The building was designed by the famous German architect Karl Schinkel in the early 1800s, destroyed during World War II and rebuilt in the early 1980 s.

Berlin's new Central Station, Europe's largest and newest train station, designed by von Gerkan, Marg and Partners. (source: http:// en.wikiarquitectura.com)

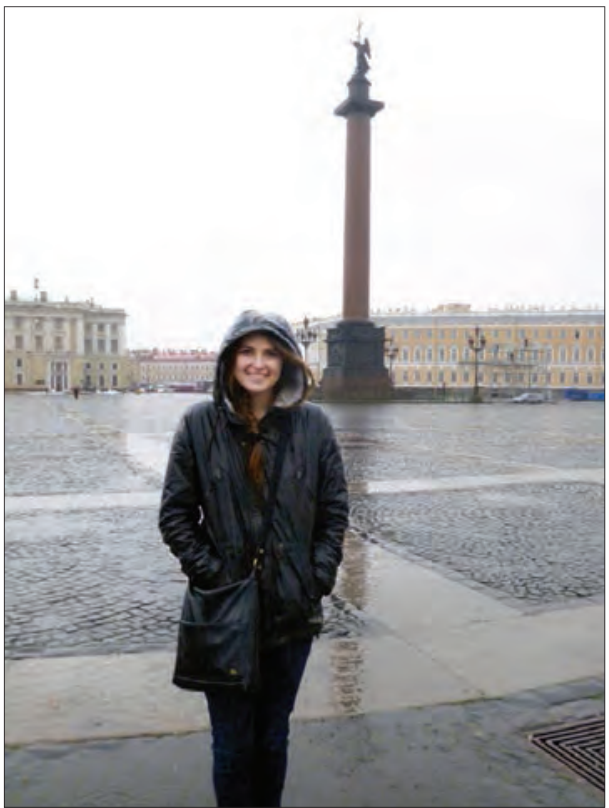

Kirsten in front of the Hermitage Museum, at the Palace Square in St. Petersburg, Russia.

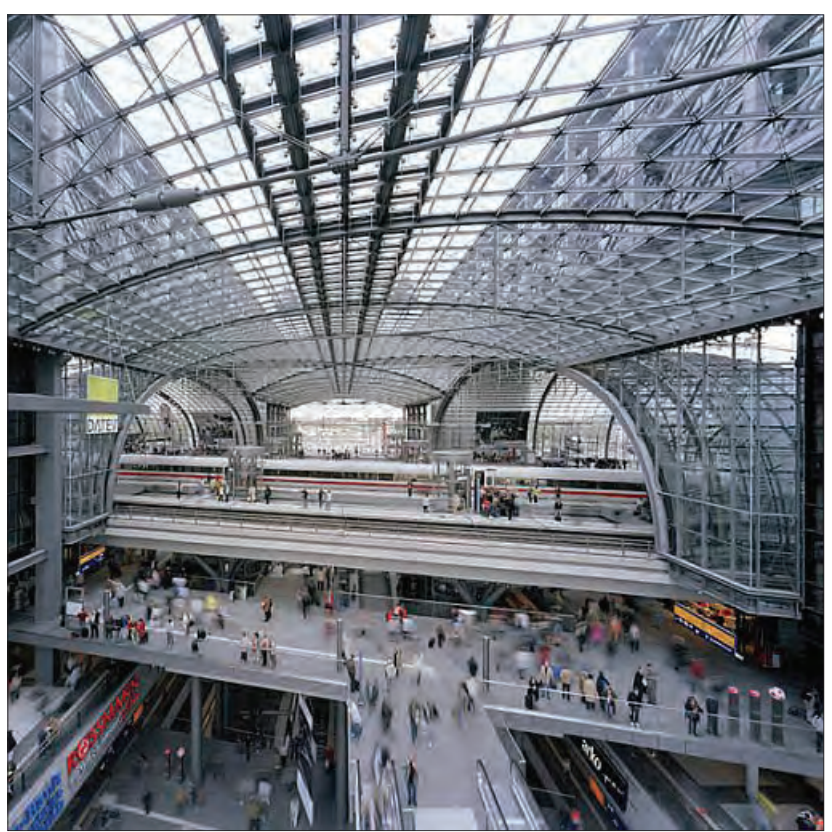

